\title{
FABRICATION AND EVALUATION OF MECHANICAL PROPERTIES FOR NATURALLY AVAILABLE FIBRES AND GLASS FIBRE
}

\author{
HARISH S R ${ }^{1}$, SHYAM SUNDER $\mathbf{N}^{2}$, SURESH $\mathbf{R}^{3}$ \& SHRISHAIL B KAKKERI ${ }^{4}$ \\ ${ }^{I}$ M.Tech. (Student), Department of Mechanical Engineering, Sri Venkateshwara \\ College of Engineering, Vidyanagar, Bengaluru, India \\ ${ }^{2,3}$ Assistant Professor, Department of Mechanical Engineering, Sri Venkateshwara \\ College of Engineering, Vidyanagar, Bengaluru, India \\ ${ }^{4}$ Professor \& Head, Department of Mechanical Engineering, Sri Venkateshwara \\ College of Engineering, Vidyanagar, Bengaluru, India
}

\begin{abstract}
A significant number of our present day advancements request materials with an abnormal blend of properties for example, immense quality to weight proportion, huge, more erosion defiance, great weakness, quality immense, dimensional strength and so on. these can't be met by the traditional metal combinations. As of late European Union (E.U) and Asian nations have discharged stringent standards concerning car end-life necessities i.e., the parts of the automotives can be reused. This expanded the utilization of regular filaments in composite materials. Characteristic filaments have turned out to be more appealing to specialists, architects and researchers as an option support for fiber strengthened polymer composites. Because of their ease, low thickness, solidness, genuinely great mechanical properties, high particular quality, non-rough, eco-accommodating and ecological attributes, they are misused as a trade for the regular fiber. This paper deals with the evaluation of mechanical properties of epoxy matrix composite fortified with Jute / Hemp / Bamboo and glass fibers were evaluated. These filaments were put with grid tar by utilizing hand lay-up system. In this exploration the mechanical equities like flexural strength, impact strength, tensile strength, inter laminar shear strength and hardness tests were contemplated according to ASTM standards.

KEYWORDS: Jute Fiber, Hemp Fiber, Bamboo Fiber, Glass Fiber, Hand Lay-Up System, Ecological, Epoxy Matrix \& Mechanical Properties
\end{abstract}

Received: Jun 17, 2017; Accepted: Jul 10, 2017; Published: Jul 27, 2017; Paper Id.: IJMPERDAUG201726

\section{INTRODUCTION}

The improvement of composite material and their relevant plan and assembling advances are standout amongst the largest vital advantages ever. Composites are the material utilized as a part of different sectors having elite mechanical and physical assets and are created for specific appliance. Composite materials having a scope of favourable circumstances against other ordinary materials for example rigidity, affect quality, flexural qualities, solidness and exhaustion attributes. In light of their various points of interest they are broadly utilized as a part of the aeronautic trade, business mechanical building applications, similar to machine segments, autos, ignition motors, mechanical segments such as drive shafts, tanks, damper, liners and balancing systems, warm regulation and voltaic bundling, railroad mentors including flying machine design and so on.

Whenever at least two substances plus various properties are consolidated well-balanced, they frame a 
composite material. Composite materials involve solid load conveying substance (reinforcement) ingrained with weakened substances (matrix). The essential elements of the lattice are, to transfer worries within strengthening filaments as well as it acts as a safeguard for mechanical, including common mischief while the nearness of strings in a composite enlarge its mechanical assets like elasticity, flexural quality, affect quality, firmness and so on.

Composites can be arranged by various criteria. Contingent upon the kind of matrix substances, composite materials can be arranged into 3 classes, for example, metal form, polymer form and ceramic forms. Particular sort of composite material is reasonable for particular appliances. At the point while the grid substantial is seized as alloy prefer aluminum, titanium, it is called as lattice composite. It possesses eminent pliability and quality, great break sturdiness furthermore includes prevalent electrical and warm potential. It is eminent spatial safe because of less warm development contemporary framework and hold off great warmth. Because of the great versatile modulus of fortifications, it has immense solidness. At the point while the framework substance is employed as earthenware known as clay lattice composite. These materials incorporate an immense collection of dead ingredients. These substances are ordinarily not silvery. This is prepared all the time at high temperature. The primary goal in delivering earthenware lattice composites is to improve the durability, immense quality and firmness, great warmth assets, wear resistance and So on.

In light of the sorts of support polymer composite can be delegated crude strengthened polymer composite and fiber fortified polymer composite Molecule strengthened compounds likewise termed as crude compound comprising of fortifying component that is in the frame molecule. The condition of strengthening molecule can either be cycle a platelet square tetragonal or of another standard or flighty division. The strategy of the molecules in the compounds can be either subjective or favored presentation. Overall, molecules are utilized as a piece of composites to change the warm and electric potentials, enhance execution at lifted hotness, decrease disintegration, raise corrosion and scratched spot defiance upgrade escalation of exterior toughness and abatement contraction.

Fibre reinforced polymer composites also termed as coarse compounds subsists of filaments as the reinforcement Presently a days these compounds acquired discovered functions in different territories, for example car marine, aviation and so forth because of their high particular solidness and quality By and large, strands are the best essential fly of fortifications in compound substantial's as they fulfill the coveted environment and exchange quality to the framework factor impacting and upgrading their coveted possessions. A fiber is portrayed by its limit being substantially more prominent when contrasted with its short division measurements. The assets of lattice fiber and its fuse possesses significantly impacting the equities of compound material.

Composites made of the identical strengthening component framework cannot permit superior outcomes as it experiences, diverse stacking environment amid the administrative entity. With a specific end goal to take care of this issue half and half composites are the perfect answers for specific functions. A half breed compound is a blend of at least 2 unique sorts of fiber in which one kind of fiber adjust the inadequacy of other fiber The motivation behind graft is to build another component that will hold the upsides of its elements however not their disservices The idea of graft offers adaptability to the plan designer to couturier the component equities as indicated by the necessities, which is one of the real points of interest of composite. 


\section{Objectives of the Work}

The objectives of the work are defined under.

- Fabrication of a different fly of epoxy stationed composites such as jute-hemp-bamboo and jute-glass-hemp fibres reinforced hybrid composites.

- Fabrication of Composites of various compositions using simple hand lay-up technique.

- To estimation of mechanical possessions such as impact strength, tensile strength, flexural strength, hardness and also inter laminar shear strength.

\section{MATERIALS AND METHODS}

\section{Materials}

The principal target is to choose common strands which are accessible effectively and eco-accommodating. Henceforth we have chosen the generally accessible strands for example, bamboo hemp, jute and glass fiber. The most received epoxy resins (Lapox L-12) and hardener (K-6) are utilized to create the covered sheets and hybrid combinations. Epoxy resin (Lapox L-12) having the accompanying remarkable properties have been utilized as the network material.

The crude materials utilized as a part of this work are:

- Jute fiber

- Hemp fiber

- Bamboo fiber

- Glass fiber

- Epoxy resin and

- Hardener

\section{Fabrication Technique}

Hand lay-up is the least difficult also best established unfastened embellishment plans of action for the composite assemble shapes. It is a less capacity, task serious strategy adapted specifically for substantial sections. Glass or another fortifying spun structure or meandering is adapted substantially in the unfastened form and tar is drained, scraped or showered. Occupied wind air is expelled substantially with squeegees to accomplish the envelope format. Room warmth curing polyesters and epoxies are the best normally employed framework gums. Curing is begun by an impetus in the tar core which stiffens the string fortified pitch composite beyond outside affection. For a brilliant part facial a brunet transpire fleece is first affiliated to the exterior shape. The grip layup method is the most straightforward method for preparing UPsaps into conclusive items. It doesn't require a broad interest in gear happens at room temperature and is utilized for a wide assortment of items. It is an open shape prepares additionally called contact forming. It is a generation procedure appropriate for models and low volume creation of fiber composite material parts. The composite part will have a decent smooth surface on one side and a harsh one on the other. The strands are physically put into an uneven gel covered male or female form. A lattice of thermo setting sap is moved onto the fiber utilizing a hand roller. More layers can be included and in the wake of drying the composite part can be expelled from the shape. 


\section{Fabrication of Composite}

The composites are created with jute, bamboo, hemp and glass fiber as a fortification and epoxy tar is utilized as a framework material. The mechanical equities of the composites are basically affected through the fiber willing in the composites. So that the composite is set up according to the ASTM standard measurements.

\section{The Various Stages Involved in Hand Lay-Up Process are as Follows}

Stage 1: Cut down the strands according to the required Length.

Stage 2: Place the elastic at the edges.

Stage 3: Lay up the blend of particular parent fiber sand mixture mixes of required extents over the polythene Sheet. Figure 1 demonstrates procedure of hand lay-up technique.

Stage 4: Pour the epoxy pitch consistently and put another polythene sheet over it.

Stage 5: Allow a Curing time of around 20-24 hours and afterward isolate the composite plate.

Broad venture is not required for hand lay-up procedure and process happens at room temperature. It is utilized for a wide assortment of items. It is additionally called as contact trim. This creation system is low volume generation of fiber composite material. It is appropriate for models. The got composite part will have a decent smooth surface on both sides. Subsequently healing composite was removed from the mould and the samples were cut according to the ASTM standards.

\section{Testing of Composites}

In the present exploratory work the composite material is manufactured utilizing hand lay-up strategy. The test examples are set up according to the ASTM principles and are tried to assess the mechanical properties like rigidity, flexural quality, entomb laminar shear quality, affect quality, hardness, moister retention and fire getting test. An example of the readied composite material is to be tried with a general testing machine for extreme rigidity and flexural quality. The test examples are held in the machine and the load is connected. The load at which the composite material failure occurs is noted down for the further discussions.

Table 1: Laminates Designations

\begin{tabular}{|l|c|}
\hline Composites & Compositions \\
\hline C1 & Glass + jute + hemp fibres \\
\hline C2 & Jute + hemp + bamboo fibres \\
\hline
\end{tabular}

\section{RESULTS AND DISCUSSIONS}

Tensile Properties

The composites examples $\mathrm{C} 1$ and $\mathrm{C} 2$ are tested in UTM for tensile properties. The acquired tensile possessions are appeared in Table 2. The mechanical possessions like breaking load, tensile modulus and ultimate tensile strength (UTS) are appeared in Table 2. The stress versus strain graph is appeared in Figure 1. The Laminate C1 which comprises of unadulterated glass fibres demonstrates immense tensile strength of $19.89 \mathrm{~N} / \mathrm{mm}^{2}$ and C2 which comprises of unadulterated bamboo fiber demonstrates a lower rigidity of $15.35 \mathrm{~N} / \mathrm{mm}^{2}$. Here the mixture of glass/jute/hemp fiber laminate $\mathrm{C} 1$ shows better results than the mixture of jute/hemp/bamboo fiber composite $\mathrm{C} 2$. 


\section{Flexural Properties}

The flexural assets containing flexural modulus and ultimate flexural strength (UFS) of composites $\mathrm{C} 1$ and $\mathrm{C} 2$ are organized in Table 3. Stress versus strain graphs appear in Figure 2. The Laminate C1 demonstrates a high flexural strength of $82.35 \mathrm{~N} / \mathrm{mm}^{2}$ and $\mathrm{C} 2$ which demonstrates a lower flexural strength of $50.57 \mathrm{~N} / \mathrm{mm}^{2}$. But the combination of jute/glass/hemp tiers laminates $\mathrm{C} 1$ shows superior outcomes than the mixture of jute/hemp/bamboo fibers composite $\mathrm{C} 2$.

\section{Impact Property}

The debt of vitality while impact is the vitality consumed by the sample. The qualities are arranged in Table 4 . Figure 3 demonstrates a correlation within vitality consumed by the diverse blend of composites. The composite $\mathrm{C} 1$ indicates immense impact strength than the other composite C2. The impact strength for composite $\mathrm{C} 1$ is. $03649 \mathrm{~J} / \mathrm{mm}^{2}$ which better than composite $\mathrm{C} 2$ of $0.02515 \mathrm{~J} / \mathrm{mm}^{2}$.

\section{Inter Laminar Shear Strength (ILSS)}

Table 5 demonstrates ILSS comes about for various mixes of composites. The load versus length graphs are displayed in Figure 6 and stress versus strain graphs are plotted in Figure 4. The C1 demonstrates better ILSS of 101.3 $\mathrm{N} / \mathrm{mm}^{2}$. It is better than composite $\mathrm{C} 2$ which shows ILSS of $40.72 \mathrm{~N} / \mathrm{mm}^{2}$.

\section{Hardness Test (BHN)}

Figure 5 shows the hardness of composites $\mathrm{C} 1$ and $\mathrm{C} 2$. Table 6 represents the hardness values obtained for composite $\mathrm{C} 1$ and $\mathrm{C} 2$. The composite $\mathrm{C} 2$ exhibits maximum hardness number of $21.34 \mathrm{BHN}$ when compared to other composite $\mathrm{C} 1$ of $17.91 \mathrm{BHN}$. This might be because of uniform scattering of particles and great holding quality amongst fiber and network. Be that as it may, hardness of composite $\mathrm{C} 1$ diminished as a result of porosity and powerless bond quality between the grid and fortifications.

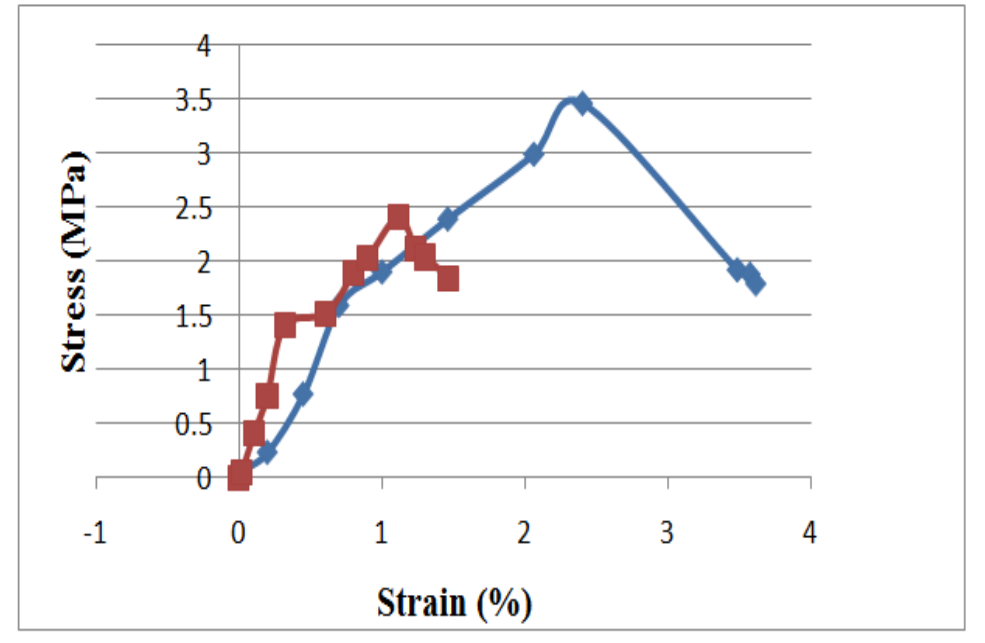

Figure 1: Stress vs Strain for Tensile Test

Figure 1, depicts the stress v/s strain graph for tensile test. It shows that, the stress linearly increases with increase in amount of strain for $\mathrm{C} 1$ and $\mathrm{C} 2$. Then the value of the stress value going down while the strain was more increased for $\mathrm{C} 2$. This is owed to the weak interface area and micro arena raised within the fiber and the matrix. 


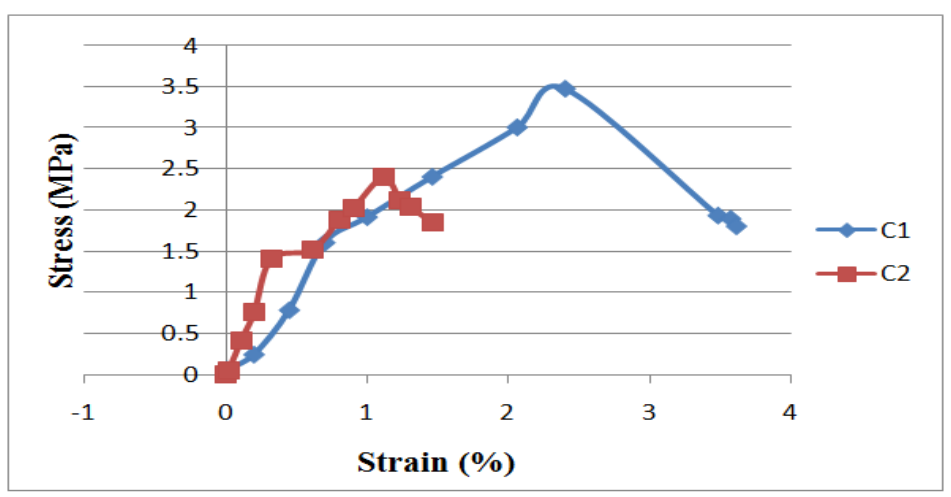

Figure 2: Stress vs Strain for Flexural test

Figure 2 depicts, the stress v/s strain graph for tensile test. It shows that, the stress increased with an increase in the amount of strain. For $\mathrm{C} 1$ the stress moderately increased and then starts going down, and for C2 after some amount of strain, stress starts coming down. This May be due various kinds and compression fibres.

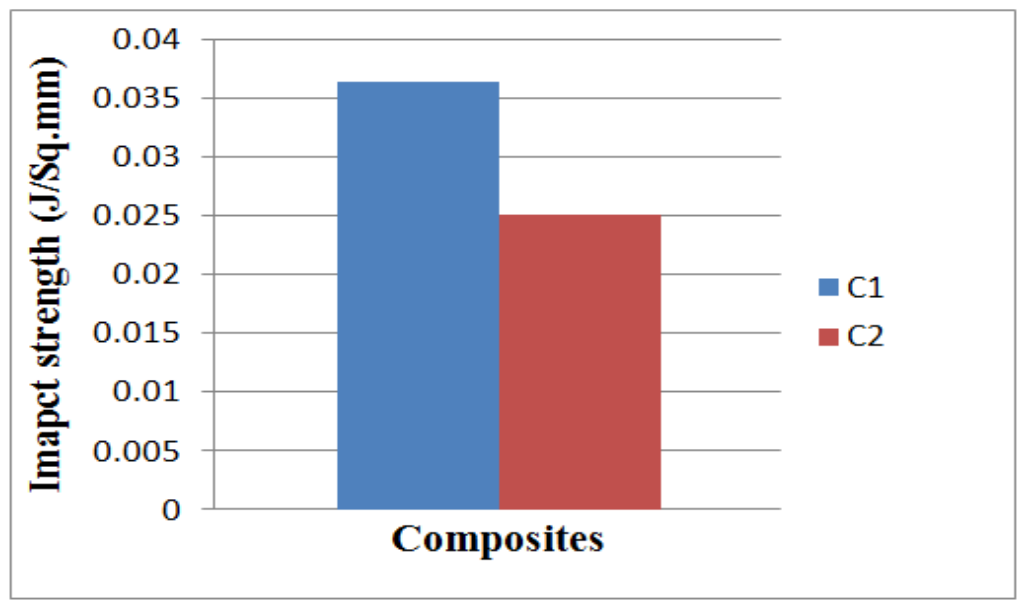

Figure 3: Impact Strength of Composites

Figure 3 depicts, the stress v/s strain graph for tensile test. As you can see from the graph, the impact strength of $\mathrm{C} 1$ is high, due to good bond within the fiber and matrix.

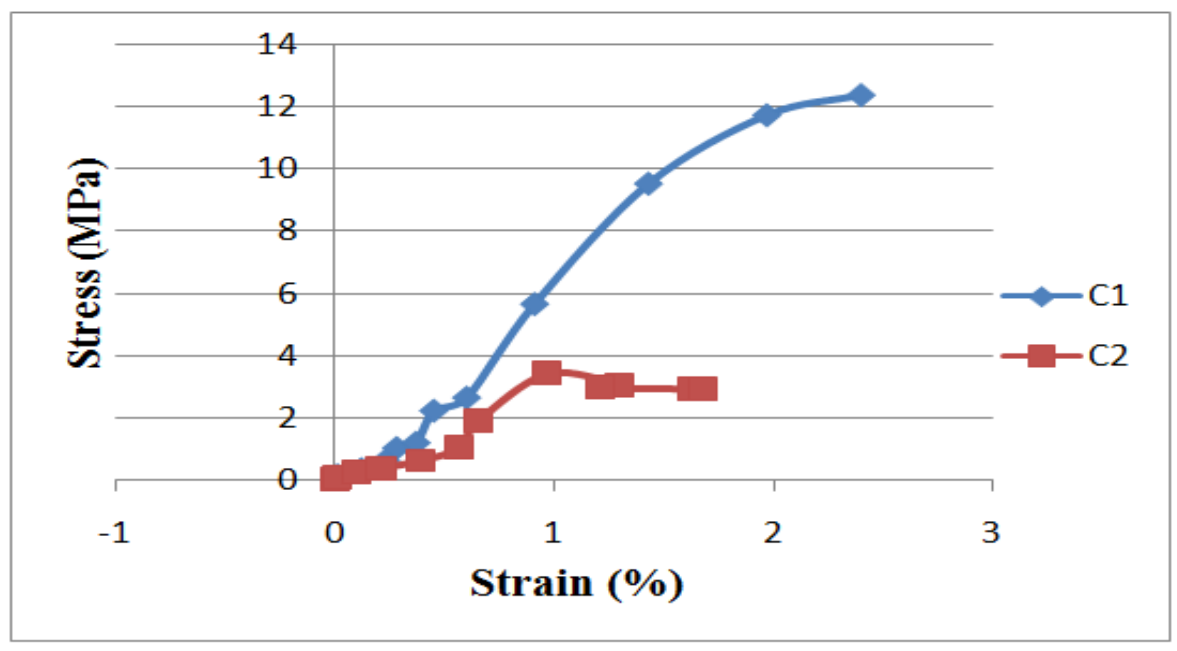

Figure 4: Stress vs Strain for ILSS 
Figure 4, depicts the stress v/s strain graph for tensile test. The stress is gradually increasing with increase in strain. The composite $\mathrm{C} 1$ has high stress and strain compare to composite $\mathrm{C} 2$. After some value of strain the stress is going down due poor circulation of resin with fiber thus leading to poor mechanical properties.

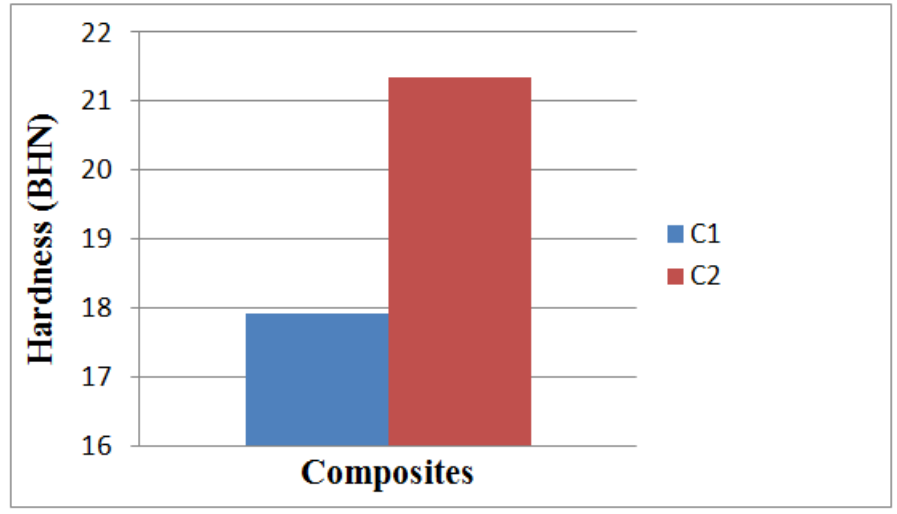

Figure 5: Hardness of Composites

Figure 5 depicts the hardness number for composite $\mathrm{C} 1$ and $\mathrm{C} 2$. Here the hardness number for $\mathrm{C} 2$ is high, due to proper bonding between the fiber and matrix. This leads to get better hardness value.

Table 2: Tensile Properties of Composites

\begin{tabular}{|c|c|c|c|}
\hline Composites & Break Load $(\mathbf{N})$ & Tensile Modulus $\left(\mathbf{N} / \mathbf{m m}^{\mathbf{2}}\right)$ & UTS (N/mm $\mathbf{~})$ \\
\hline C1 & 1114.35 & 4880.64 & 19.89 \\
\hline C 2 & 1074.86 & 4557.12 & 15.85 \\
\hline
\end{tabular}

Table 3: Flexural Properties of Composites

\begin{tabular}{|c|c|c|}
\hline Composite & Flexural Modulus (GPa) & UFS (N/mm $\left.\mathbf{~}^{\mathbf{}}\right)$ \\
\hline $\mathrm{C} 1$ & 5176.86 & 82.25 \\
\hline $\mathrm{C} 2$ & 4876.52 & 50.57 \\
\hline
\end{tabular}

Table 4: Impact Strength of Composite

\begin{tabular}{|c|c|}
\hline Composites & Impact Strength $\left(\mathbf{J} / \mathbf{m m}^{2}\right)$ \\
\hline $\mathrm{C} 1$ & 0.03649 \\
\hline $\mathrm{C} 2$ & 0.02515 \\
\hline
\end{tabular}

Table 5: Inter Laminar Shear Strength of Composites

\begin{tabular}{|c|c|}
\hline Composites & ILSS $\left(\mathbf{N} / \mathbf{m m}^{2}\right)$ \\
\hline $\mathrm{C} 1$ & 101.83 \\
\hline $\mathrm{C} 2$ & 40.72 \\
\hline
\end{tabular}

Table 6: Hardness (BHN) of Composites

\begin{tabular}{|c|c|}
\hline Composites & Hardness (BHN) \\
\hline $\mathrm{C} 1$ & 17.91 \\
\hline $\mathrm{C} 2$ & 21.34 \\
\hline
\end{tabular}

\section{CONCLUSIONS}

This paper presents the fabrication of hybrid composite using jute, E-glass, hemp fibers and jute, hemp and bamboo fibers reinforced with epoxy composite by hand layup method. 


\section{From all the Investigations, the Successive Outcomes are Made}

- The composite $\mathrm{C} 2$ of jute, hemp and bamboo fibers composition demonstrates authentic bad outcomes than composite $\mathrm{C} 1$ of Jute, E-Glass, and Hemp fibers half breed composition. This may be because, glass is used as an outer layer for $\mathrm{C} 1$.

- The fusion of glass string in bamboo filament composites improves the mechanical properties and it prompts the expansion of the use of ordinary filaments, in different appliances.

- The consequences of the jute-glass-hemp composite was contrasted against the consequences of jute-hempbamboo epoxy composite. It was demonstrated that, when the ordinary string (bamboo) and man made string (EGlass) are fused upon epoxy pitch it indicated preferred quality firmness over ordinary string (Bamboo) fortified epoxy resin.

\section{ACKNOWLEDGEMENTS}

We express our earnest on account of my dearest guardians, for their important love; moral support and consistent consolation in my life. We owe huge appreciation to our essential Dr. Shrishail B Kakkeri, Prof. And Head, Department of mechanical Engineering, SVCE, Bengaluru, for his ethical support throughout my Research work. Our sincere thanks to Shyam Sunder N and Suresh R, Assistant Professor, Department of Mechanical Engineering, SVCE, Bengaluru and Ravikumar M, Assistant Professor, Department of Mechanical Engineering, SJCIT, Chickballpura, for their significant guidance and suggestions.

We might want to thank the reviewers of this article framework, for their important sources of info and remarks.

\section{REFERENCES}

1. Ajith Gopinath, Senthil Kumar. M, Elaya Primal A. Experimental Investigations on Mechanical Properties Of Jute Fiber Reinforced Composites with Polyester and Epoxy Resin Matrices. Procedia Engineering 97; 2014; 2052 - 2063 ; doi: 10.1016/j.proeng.2014.12.448.

2. [2] Sanjay M R, Arpitha GR \& B Yogesha. Study on Mechanical Properties of Natural - Glass Fibre Reinforced Polymer Hybrid Composites: A Review. Materials Today: Proceedings 2; 2015; 2959 - 2967; doi: 10.1016/j.matpr.2015.07.264.

3. Santulli C. (2001). Post-impact damage characterisation on natural fibre reinforced composites using acoustic emission. NDT \& E International, Vol.34(8), pp. 531-536.

4. Hanafi Ismail, M.R. Edhyam, B. Wirjosentono. Bamboo fiber filled natural rubber composites: the effects of filler loading and bonding agent. European polymer journal 38; 2002; 39-47.

5. Gowda, T. M., Naidu, A. C. B., \& Chhaya, R. (1999). Some Mechanical Properties of Untreated Jute Fabric-Reinforced Polyester Composites. Composites Part A: Applied Science and Manufacturing, Vol.30(3), pp. 277-284.

6. Huang, G. \& Sun, H. (2007).Effect of water absorption on the mechanical properties of glass/polyester composites. Materials \& design, Vol.28, pp.1647-1650

7. Wang, Y., Li, J. \& Zhao, D. (1995). Mechanical properties of fibre glass and Kevlar woven fabric reinforced composites. Composites Engineering,Vol.5(9), pp.1159-1175.

8. Varma, I. K., Anantha Krishnan, S. R. \& Krishnamoorthy, S. (1989). Composites of glass/modified jute fabric and unsaturated polyester resin. Composites, Vol.20 (4), pp.383-388 
9. Dixit S. \& Verma P.(2012). The effect of hybridization on Mechanical Behaviour of coir/sisal/jute Sfibres reinforced polyester composite materials. Research journal of chemical sciences, Vol.2(6),pp.91-93

10. Thwe, M. M. \& Liao, K. (2000). Characterization of bamboo-glass fibre reinforced polymer matrix hybrid composite. Journal of materials science letters, Vol.19(20), pp. 1873-1876

11. Sreekala, M. S., George, J., Kumaran, M. G. \& Thomas, S. (2002). The mechanical performance of hybrid phenolformaldehyde-based composites reinforced with glass and oilpalm fibres. Composites science and technology, Vol.62(3), pp.339-353 
